Vietnam Journal of Earth Sciences, 39(1), 1-13, DOI: 10.15625/0866-7187/39/1/9167

Vietnam Academy of Science and Technology
Vietnam Journal of Earth Sciences
http://www.vjs.ac.vn/index.php/jse

\title{
Eruptive-volcanic-basalt structures in the Truong Sa- Spratly Islands and adjacent areas from interpreting gravity and magnetic data
}

\author{
Tran Tuan Dung*1, 2, Nguyen Quang Minh ${ }^{1}$ \\ ${ }^{1}$ Institute of Marine Geology and Geophysics, Vietnam Academy of Science and Technology \\ ${ }^{2}$ Graduate Universiy of Science and Technology, Vietnam Academy of Science and Technology
}

Received 28 April 2016. Accepted 20 January 2017

\begin{abstract}
In the Spratly Islands (Truong Sa Islands) and adjacent areas, volcanic activities are quite strong after the seafloor spreading in the Cenozoic Era. However, it is difficult to define their ranges and spatial locations. Based on the different characteristic between eruptive volcanic basalt and sedimentary rocks near the surface, it can be said that, the blocks which are higher density and magnetization than those surroundings could be identified as eruptive volcanic basalt. This paper presents the methods of reduction to the magnetic equator in low latitudes to bring out a better correlation between magnetic anomalies and their causing-sources; High-frequency filtering is to separate gravity and magnetic anomalies as well as information about the volcanic basalts in the upper part of the Earth's crust; 3D total gradient is to define the spatial location of high density and magnetic bodies. The potential structures of eruptive volcanic basalt are predictively determined by multi-dimensional correlation analysis between high-frequency gravity and magnetic anomalies with weighted total gradient $3 \mathrm{D}$. The results from the above-mentioned methods have shown that the distribution of the eruptive volcanic basalt mainly concentrates along the Spratly Island's seafloor-spreading axis, transitional crust, Manila trench and some large fault zones. These results are improved by available seismic data in the study area.
\end{abstract}

Keyword: Spratly Islands, Reduction to the equator, 3D total gradient, Eruptive volcanic basalt.

(C)2017 Vietnam Academy of Science and Technology

\section{Introduction}

The East Vietnam Sea has been formed from the collision between the Indian and the Eurasian plates. The opening process of the East Vietnam Sea leads to sea-floor spreading to form the basin. Some of these basins were

"Corresponding author, Email: trantuandung@yahoo.com opened by pull-apart mechanism resulting in lithospheric rift and separating of subcontinent as well. It is said that, the spreading process terminated in the Late Miocene after the collision among North Palawan formation and west Philippine Arc; Taiwan Island and Chinese mainland (Li S-L., et al., 2011). The initiate phase of the lithospheric rift is often 
accompanied by magmatic activities (eruption and intrusion). Volcanic activities are quite strong after sea-floor spreading and the magmatic eruption occurs not only in the Spratly Islands but also elsewhere in the Southeast Asia. The magmatic activity cut-through the ocean floor, sub-continent such as Paracel and Spratly (Hoang $\mathrm{Sa}$ and Truong Sa) Islands, Reed Bank is forming the basalt layers in the region. Many suggested that the opening process of the Spratly Islands is more complex than the existing document. Researching results from the geothermal and gravity methods show that either the rate of subsidence extremely slow or the intrusion rate of heat flow come up so high. The relationship of the time and space of magmatic field after rift has led to the question, that is, main motion for the magmatic field: the mantle uplift or the lithospheric rift? (Bui Cong Que, Tran Tuan Dung, 2008; Nguyen Hoang and PhanTrong Trinh, 2009; Li S-L., et al., 2011; Tran Tuan Dung, 2013).

The activity of basalt eruptions occurs quite commonly following the rest time of seafloor spreading in the East Vietnam Sea (from 32 to $17 \mathrm{Ma}$ ). In this region, Neogen Quaternary basalt distributes mostly along the major fault system, appear after rift and later than $6 \mathrm{Ma}$. It is a combination of stone including tholeiite basalt, olivine basalt and alkaline basalt, little basalt-andesite and high alkaline basalt (Nguyen Hoang and Phan Trong Trinh, 2009).

During the seafloor spreading process, basaltic magma of early phase was formed in the strong extension condition (high levels of partial melting), at a shallow depth (low pressure); In contrast, basalt of late phase was formed in limited extension condition (low levels of partial melting), at a deeper depth (high pressure). The difference of time and magnitude of the spreading process which decides to the characteristics the late Cenozoic basaltic activities and distribution in Vietnam: the strong eruptive activities in the southern part, as to the north as the eruptive activities decrease and mostly single eruption (Pham Tich Xuan et al., 1999, 2004).

The volcanic activities occur in multiphases and basalt eruption develops largely in the Spratly Islands and continental margins. In the Late Mesozoic, the eruptive volcanic basalt is main granite that distributes in the northern margin of the Spratly Islands, Indochina continental shelf and Paracel and Spratly islands. In the Cenozoic, types of the volcano are main basalt eruption, concentrate commonly in the continental margins and oceanic crust areas. In general, the distributional characteristics of eruptive volcanic basalt have a close relationship with the geo-tectonics activities in the Spratly Islands (Flower et al., 1992; McElhinny, 1973; Li S-L., et al., 2011; Tran Tuan Dung, 2013).

In the ocean, eruptive volcanic basalt is the main source of the local gravity and magnetic anomalies. Based on the difference of density and magnetization between volcanic basalt and sedimentary rock, geoscientists have used the geophysical methods such as gravity, magnetic and seismic to determine the location of eruptive volcanic basalt. However, due to the complex tectonic activity, the difference in the Earth's crust structure, the diversity of rock types, variations of the geophysical anomaly at low latitudes, then the application of an individual geophysical method will not be able to bring out good results. Therefore, it is necessary to apply the interpretative methods of gravity, magnetic with seismic and drilling data in combination (McElhinny, 1973; Li S-L., et al., 2011; Tran Tuan Dung et al., 2013).

In order to eliminate the inaccuracy of magnetic anomalies at low-latitudes, which caused by magnetic declination and inclination angle, some scientists have presented the methods of reduction to the magnetic equator (RTE) or pole in the spatial and frequency 


\section{Vietnam Journal of Earth Sciences, 39(1), 1-13}

domain http://geomag.org/models/emag2.html; http://www.ngdc.noaa.gov/geomag-

web/declination). The application of low/highfrequency filters allows determining the lo$\mathrm{cal} /$ regional gravity and magnetic anomaly. Here, the high-frequency anomalies are used to explain and determine the distribution of eruptive volcanic basalt (Lee et al., 1998; McElhinny, 1973).

In 1988, SudhirJain has mentioned to a number studies on the magnetic field in his research, such as: Baranov (1957) described a technique for reducing the maps made anywhere, except at very low latitudes. Into what they would be if the inclination of the magnetic field were 90 degrees. These maps are called reduced to the pole maps and the process is called reduction to the pole (RTP). Over the years, several refinements and other methods of RTP, such as techniques using Fourier transforms (Bhattacharyya, 1966: Spector and Grant, 1970) have been suggested. Leu (1981) proposed reduction to the equator (RTE) and demonstrated that RTE is more reliable at high latitudes than RTP is at low latitudes (Sudhir Jain, 1988).

In that research, Sudhir Jain gave out the equations and describe a model study to compare RTP (using conventional Baranov and Fourier transform operators) with RTE (using only Fourier transform operators). It is shown that RTE is more accurate than RTP even at high latitudes and that the Fourier transform provides more accurate RTP at lower latitudes than a conventional operator (Sudhir Jain, 1988). In general, reduction to the equator is preferable to reduction to the pole, more particularly at the middle and lower latitudes.

\section{Data}

The main gravity, magnetic and seismic data sources in the Spratly Islands are from the marine surveys of the Russian, Vietnam, French, German, United States and Japan geophysical companies. In the Vietnam Marine Research Programs, which carried out by the Institute of Marine Geology and Geophysics in recent years, such as KHCN-06-12, KC09-02, KC09-11/11-15 are also collected, interpreted and added the new research results and the valuable geophysical data in the Spratly Islands and adjacent areas (Bui Cong Que, Tran Tuan Dung, 2008, Nguyen Hoang and Phan Trong Trinh, 2009; Tran Tuan Dung et al., 2013).

In this paper, the authors have combined the satellite gravity and magnetic with shipboard data in order to bring out a data set of the satellite-shipboard-derived, which have a higher accuracy and uniform resolution, in the Spratly Islands. In recent years, United Stage scientists have built a new gravity, bathymetric grid with an interval of $1^{\prime} \times 1^{\prime}$ (David Sandwell V23.1) (Sandwell et al., 2013), (Figure 2a, 2b). The magnetic data (EMAG2) get from the NOAA's National Geophysical Data Center. EMAG2 is a global Earth Magnetic Anomaly Grid that compiled from satellite, shipboard, and airborne magnetic surveys (Figure 3a). That is the result of global cooperative projects on geophysical data, which are frequently added and updated. One can say that it is the geophysical data sources with the most uniform resolution, wide coverage, suitable accuracy and cost to use effectively for research the geological structure in the Spratly Islands (Sandwell et al., 2013; Tran Tuan Dung, 2013).

In additions, this study also referring and using the seismic data from the oil and gas exploration surveys that carried out by the geophysical companies inside and outside Vietnam, as projects VOR93, JMSU05, PK07-08... (Bui Cong Que, Tran Tuan Dung, 2008; Tran Tuan Dung et al., 2013). The research area was selected within $109^{\circ}-118^{\circ} \mathrm{E}$ and $6-13^{\circ} \mathrm{N}$ (Figure 1). 
Tran Tuan Dung and Nguyen Quang Minh/Vietnam Journal of Earth Sciences 39 (2017)

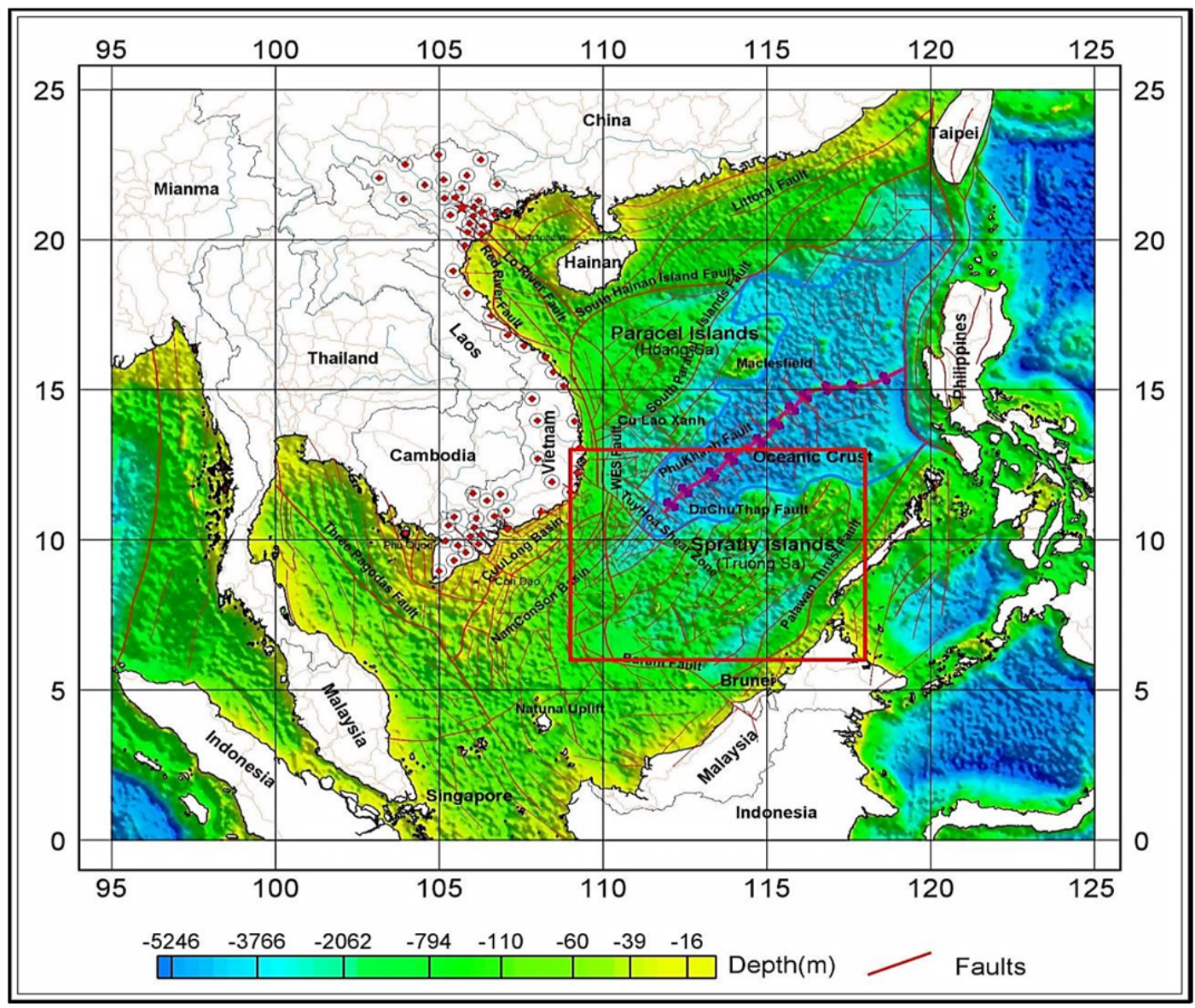

Figure 1. Location of study area (red line rectangular)

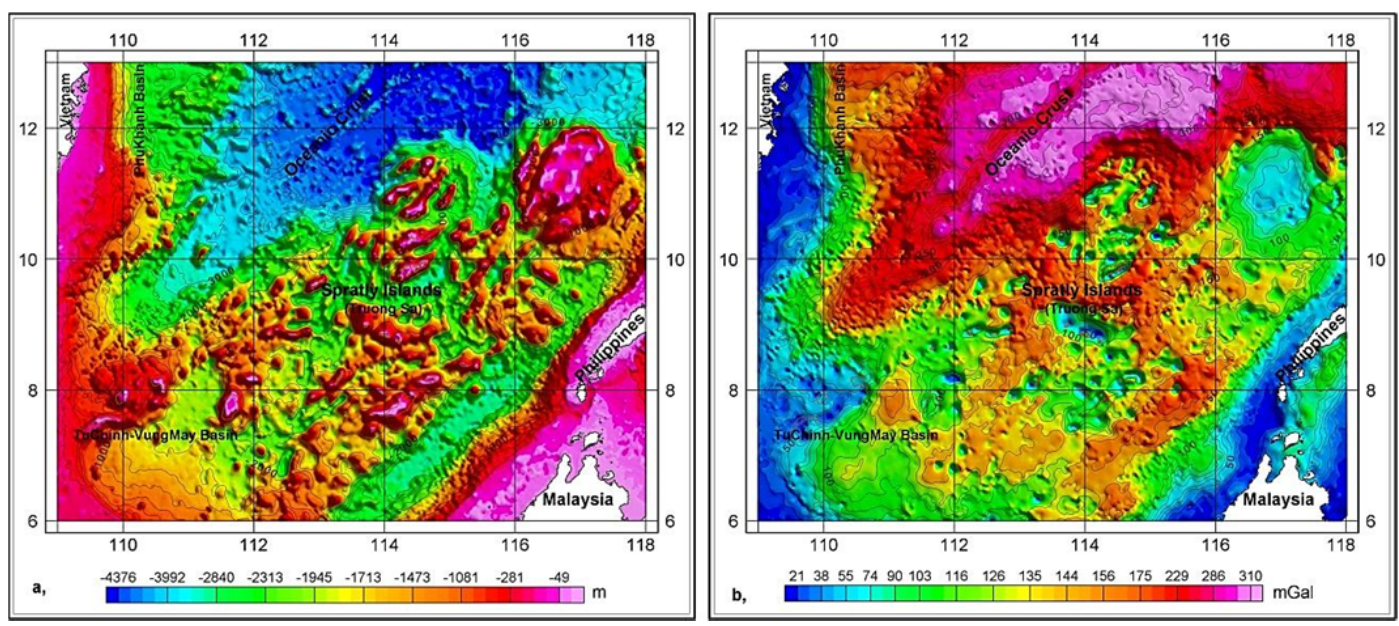

Figure 2. a) Bathymetry; b) Complete Bouguer gravity anomaly 
Vietnam Journal of Earth Sciences, 39(1), 1-13
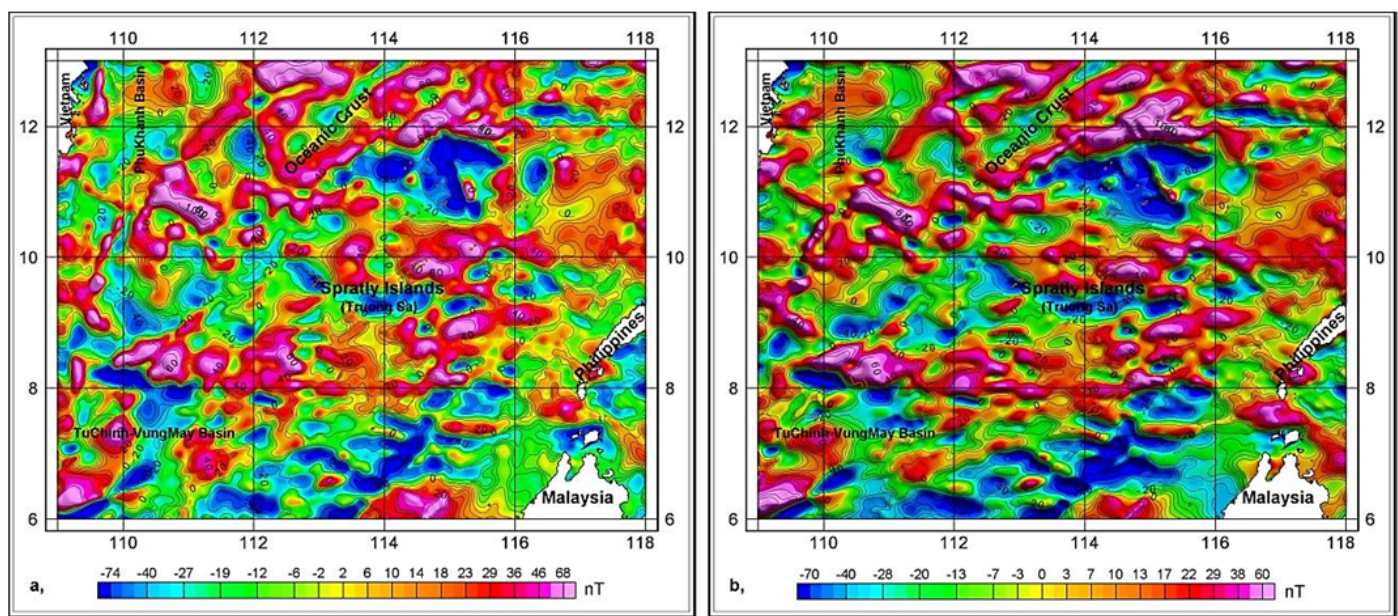

Figure 3. a) Magnetic anomaly $\Delta \mathrm{Ta}$; b) Magnetic anomalies $\Delta \mathrm{Ta}$ after reduction to the equator

\section{Applied methods}

Research and predictively determination of the distribution of eruptive volcanic basalt (including eruption or intrusion) in the Spratly Islands is a complicated problem that cannot be solved only by a single method. The research must have an overall view of the geological structure and the relationship between them and the eruptive volcanic basalts in the different phases. Therefore, it is necessary to combine geophysical methods to adjust the magnetic anomalies with their causing-source locations; to separate the anomalies, which could be caused by eruption volcanic basalts in the near Earth's surface, from the observed gravity anomaly; to determine the ranges and spatial locations of the anomaly-causing sources. This paper presents some methods as follows:

\subsection{Reduction to the magnetic Equator}

The quantitative analysis of magnetic data in the low-latitude region is encountered a difficult problem causing by magnetic inclination, that is, the anomaly locations and their sources are not coincident. Meanwhile, the study area is located in the low-latitudes near the equator, where magnetic anomalies have a poor correlation with anomaly-causing geological objects. As a result, RTE method is used to solve the above-mentioned problem. This is a method applied to the low-latitude region to adjust the magnetic anomaly locations to a best coincidence with their sources. It makes the interpretation of magnetic data more easier, which without losing their geophysical significance (http://www.ngdc.noaa.gov/geomagweb/\#declination; Karoly, 1990; Sudhir Jain, 1988; Ian N. MacLeod et al., 1993; Le Huy Minh et al., 2003).

In this research, the Geosoft package software V7.01 was used to reduce the magnetic field to equator transformation of an anomaly in the Fourier domain. The inclination and declination angles of the ambient field were taken successively in the center points of each geographic degree in the study area at the date of July 2016 according to IGRF (International Geomagnetic Reference Field), respectively.

Reduction to the magnetic equator is represented by the following formula:

$F\left\{\Delta T a_{E q}(x, y)\right\}=F\{L(\theta)\} F\{\Delta T a(x, y)\}(1)$

Where: $\mathrm{F}\{\}$ is the Fourier transform; 
$\Delta \operatorname{Ta}_{\mathrm{Eq}}(\mathrm{x}, \mathrm{y})$ is the reduced magnetic filed to the equator with $\mathrm{L}(\mathrm{x}, \mathrm{y})$ operator; $\Delta \mathrm{Ta}(\mathrm{x}, \mathrm{y})$ is the observed magnetic data; $L(\theta)$ is the operator of reduction to the magnetic equator.

The operator of reduction to the magnetic equator is calculated:

$$
L(\theta)=\frac{[\sin (I)-i \cdot \cos (I) \cdot \cos (D-\theta)]^{2} \times\left[-\cos ^{2}(D-\theta)\right]}{\left[\sin ^{2}\left(I_{a}\right)+\cos ^{2}\left(I_{a}\right) \cdot \cos ^{2}(D-\theta)\right] \times\left[\sin ^{2}(I)+\cos ^{2}(I) \cdot \cos ^{2}(D-\theta)\right]}
$$

Where: $\mathrm{D}$ is the magnetic deviation angle; $\mathrm{I}$ is the magnetic inclination angle; $\mathrm{q}$ is the wave direction; Ia is the correction angle of magnetic inclination.

The Figure $3 \mathrm{~b}$ presents magnetic anomalies after reduction to the magnetic equator. Comparing the magnetic data in the figure $3 \mathrm{~b}$ with the initial data in the Figure 3a, it can see that the magnetic anomalies after the reduction have strongly changed in both the direction and magnitude (Figure 3b).

\subsection{Frequency filtering}

The frequency filtering separates out the gravity and magnetic anomalies caused by the shallow geological objects from the total observed anomalies in order to determine the ranges and the spatial locations of the eruptive volcanic basalts, which are formed in the upper part of the Earth's crust.

Low-pass filter of gravity and magnetic anomalies are calculated by the following formula:

$\mathrm{F}\left\{\Delta \mathrm{g}_{\mathrm{LF}}(\mathrm{x}, \mathrm{y})\right\}=\mathrm{F}\{\mathrm{H}(\mathrm{x}, \mathrm{y})\} \mathrm{F}\{\Delta \mathrm{g}(\mathrm{x}, \mathrm{y})\}$

Where: $F\{\}$ is the Fourier transform; $\Delta \mathrm{g}_{\mathrm{LF}}(\mathrm{x}, \mathrm{y})$ is the low frequency anomalies that filtered with $\mathrm{H}(\mathrm{x}, \mathrm{y})$ operator; $\Delta \mathrm{g}(\mathrm{x}, \mathrm{y})$ is the complete Bouguer gravity anomaly; $\mathrm{H}(\mathrm{x}, \mathrm{y})$ is the Gaussian low-pass filter operator (Bracewell, R., 1999).

The Gaussian low-pass filter operator as follows:

$$
\mathrm{H}(\mathrm{x}, \mathrm{y})=\mathrm{e}^{-\mathrm{D}(\mathrm{x}, \mathrm{y})^{2} / 2 \lambda^{2}}
$$

Where: $\mathrm{D}(\mathrm{x}, \mathrm{y})$ is the distance between points $(x, y)$ on the gird and the center of the filtering window; $\lambda$ is cutoff wavelength.
In the next step, residual gravity and magnetic anomalies are calculated:

$$
\Delta \mathrm{g}_{\mathrm{HF}}(\mathrm{x}, \mathrm{y})=\Delta \mathrm{g}(\mathrm{x}, \mathrm{y})-\Delta \mathrm{g}_{\mathrm{LF}}(\mathrm{x}, \mathrm{y})
$$

After doing the filtering with different wavelength $\lambda$, the gravity, magnetic anomalies that correspond to these wavelengths will be used to calculate and interpret geological structures at different depths.

Here, the Geosoft package software V7.01 is applied to do low-pass filter. The high frequency gravity and magnetic anomalies are calculated for the whole area using the Gaussian low-pass filter with the filter wavelength $\lambda$. For each wavelength $\lambda$, it will bring out a distribution of geophysical anomalies at different depths. After comparing the results from the filtering in certain above-mentioned wavelengths $\lambda$, it can be seen that, the residual gravity, magnetic anomalies corresponding to the wavelengths $\lambda=50 \mathrm{~km}$ (Figures $4 \mathrm{a}, 4 \mathrm{~b}$ ) have a good correlation with the shallow geological objects. As a result, they have been applied to build the 3D total gradient model (gravity and magnetic anomalies) to determine the locations and ranges of the eruptive volcanic basalts.

\section{3. $3 D$ total gradient}

Method of 3D total gradient of gravity, magnetic anomalies is applied to determine the locations, ranges and depth of the anomaly-causing objects. However, this study refers only to their locations and ranges. There have been many studies on this problem, though, the method that presented by Nabighian, M. N., 1984, Roest et al.,1992; MacLeod et al., 1993; Phillips, J. D., 1997 are choosing to calculate the 3D total gradient of gravity, 
Vietnam Journal of Earth Sciences, 39(1), 1-13

magnetic anomalies in study area. 3D total gradient method is often used to determine the spatial location of the blocks of eruptive volcanic basalt. The Geosoft package software V7.01 was used to calculate the 3D total gradient as follows:

$\operatorname{Gra}(x, y)=\sqrt{\left(\frac{\partial A}{\partial x}\right)^{2}+\left(\frac{\partial A}{\partial y}\right)^{2}+\left(\frac{\partial A}{\partial z}\right)^{2}}$

Where: A is gravity or magnetic anomalies.

The 3D total gradient of gravity, magnetic anomalies bring out a clear picture of the spatial distribution of the eruptive volcanic basalt (in the upper part of the Earth's crust). However, to reduce the multi-solutions and improve the reliability of the method, it should have an overview analysis in combination with others geology-geophysics documents (seismic, drilling data...). The calculated result of the 3D total gradient is shown in Figure $5 a, b$.

\section{Results}

In the area, the eruptive volcanic basalts have higher density and magnetization than the surrounding rocks. The eruptive volcanic basalts that have different components, then also have a relative change in density and magnetic value. Throughout the analysis and comparison with other data sources from this research, it has found that, in the area, the eruptive volcanic basalts have a residual gravity anomaly range from +10 to $+63 \mathrm{mGal}$ and the residual magnetic range from +15 to $+185 \mathrm{nT}$, respectively (Figure 4a, b).
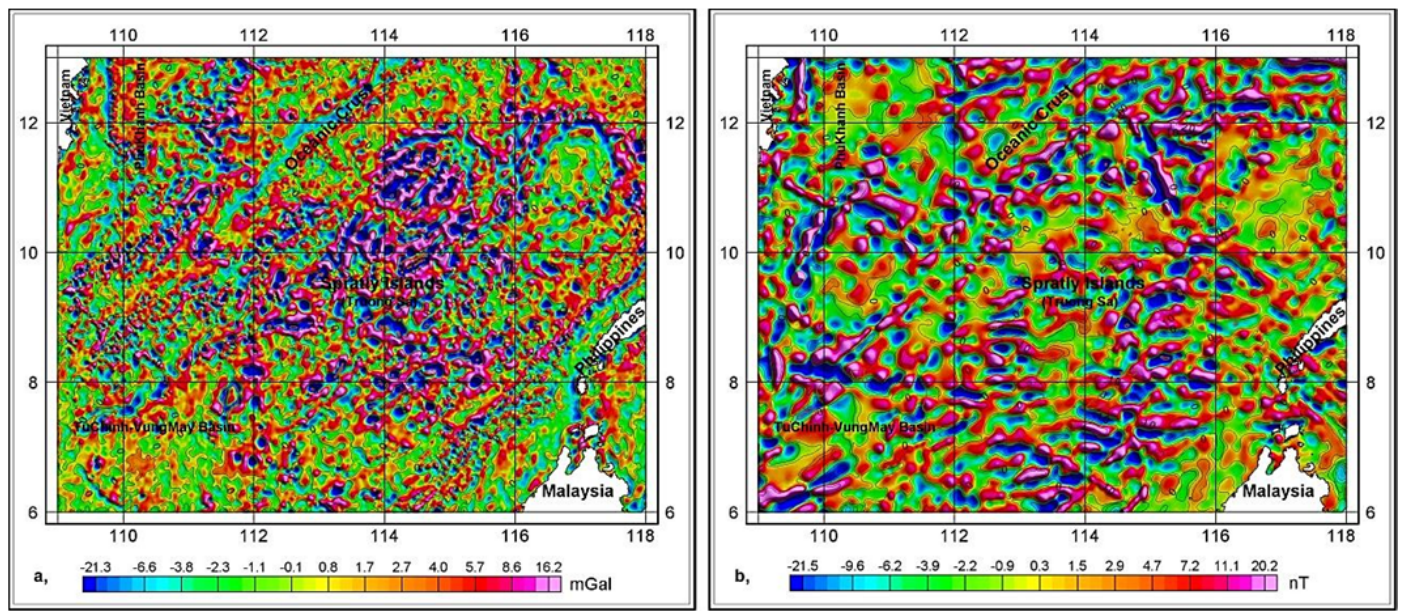

Figure 4. a) Residual gravity anomaly (filtering wavelength $\lambda=50 \mathrm{~km}$ ); b) Residual magnetic anomaly (filtering wavelength $\lambda=50 \mathrm{~km}$ )

From achieved results, the comparison among the gravity, magnetic anomalies, and their 3D total gradient is carried out to determine the spatial-coincided coefficients between them and the distribution of predictive eruptive-volcanic basalts (relative-coincident locations of the 3D total gradients with high blocks of residual gravity and magnetic anomalies). Here, the spatial-coincided coefficients have a variable range from 0.0 to 5.39 (dimensionless) (Figure 6a). Based on the comparison of the coefficient (Figure 6a) with the seismic data (Figure 6b), the authors have evaluated, interrelationship-classified in order 
to provide a detailed picture of the spatial distribution of the predictive eruptive volcanic basalt in the Spratly Islands and adjacent areas (Figure 7).
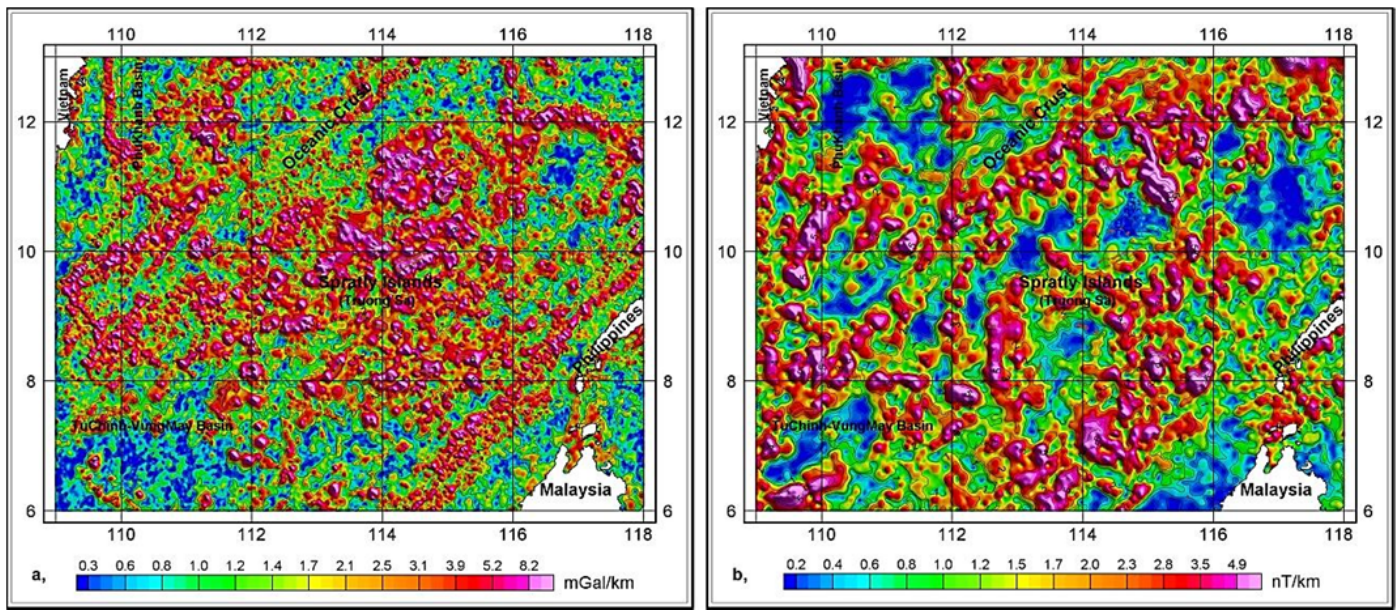

Figure 5. a) 3D total gradient of residual gravity anomaly; b) 3D total gradient of residual magnetic anomaly

Throughout the results of this research, comparing with the results of some previous study on the eruptive volcanic basalt in the Spratly Islands, which were used sparse borehole and seismic data, it has found that there are many remarkable coincidences between them. The results from the abovementioned methods have shown that the distribution of the eruptive volcanic basalt mainly concentrates along the Spratly Islands' center, transitional crust, Palawan trench and at some large fault zones.

In this research, the red-marked circles are the best correlation between the eruptive volcanic basalts and geophysical fields, which have high correlation coefficients, they are supposed to be the spatial locations of the eruptive volcanic basalt, they have high density and magnetism (Figure 7).

In Figure 7, one can see that the eruptive volcanic basalt distributes in the whole study area but not alike. Commonly, they are concentrated mainly in the area of the continental slopes, slope of the deep basin and around the Spratly Islands. Otherwise, they are very so spare in the Phu Khanh and Vung May Basins. One can see, in the Northern part, the eruptive volcanic basalts only appear incoherently on the oceanic crust of the East Vietnam Sea, but they concentrate as a large zone in the tail of the South-East oceanic crust. In the center area, the eruptive volcanic basalts are quite concentrated in the North and South part of the Spratly Islands. In the Western part, eruptive volcanic basalt appears along to Tuy Hoa shear zone, Tu Chinh, and Nam Con Son uplift. In the South of the study area, it is hard to find the volcanic basalt locations, except areas near Borneo-Palawan subduction zone. Similarly, in the Eastern part, they almost do not appear on the Reed Bank block and continental shelf of Malaysia and Philippines. 
Vietnam Journal of Earth Sciences, 39(1), 1-13
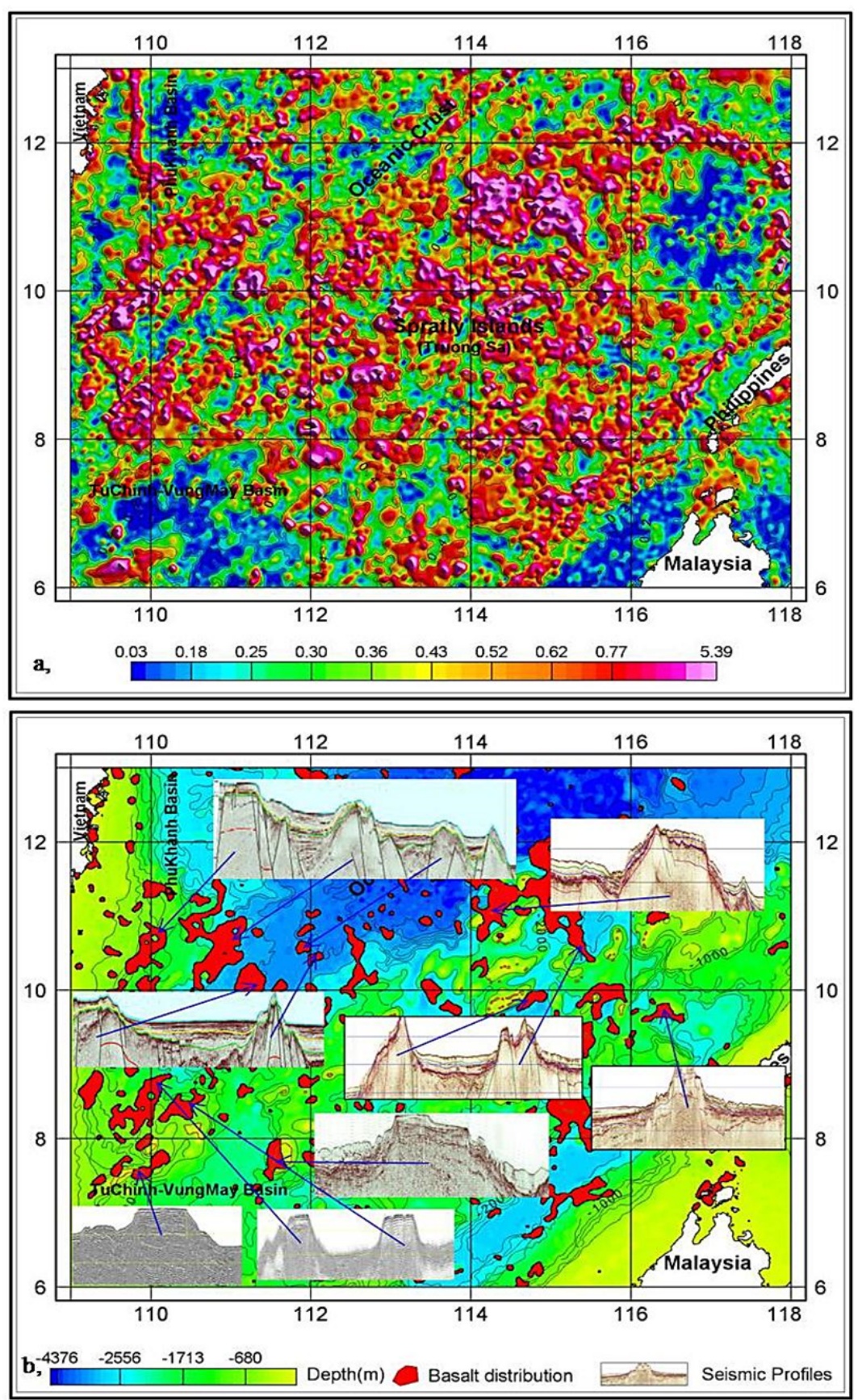

Figure 6. a) Spatial-coincided coefficients between high-frequency gravity, magnetic anomalies and their 3D total gradient with distribution of predictive eruptive volcanic basalt; b) Eruptive volcanic basalt locations showing in the known seismic and drilling data 
Tran Tuan Dung and Nguyen Quang Minh/Vietnam Journal of Earth Sciences 39 (2017)

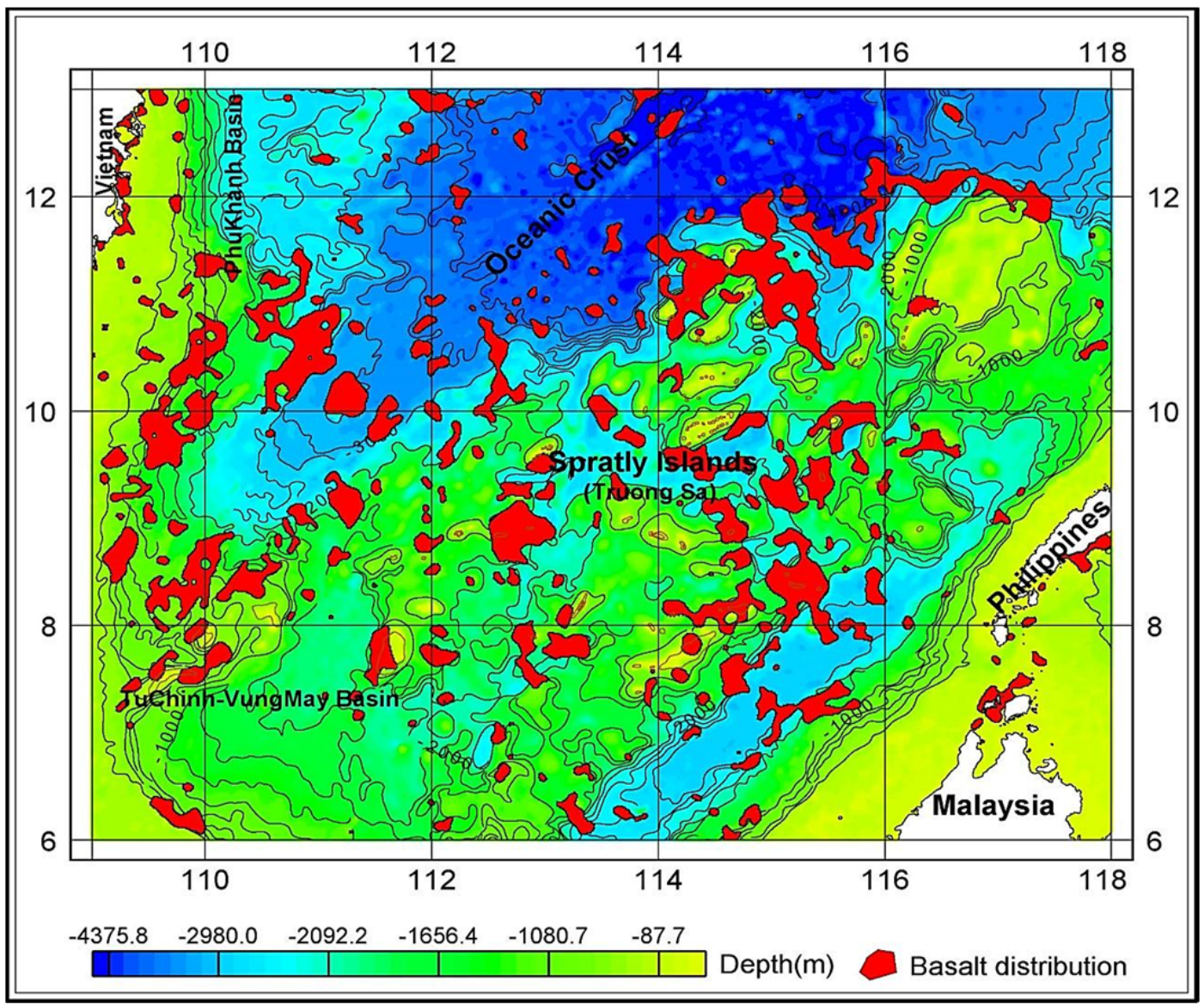

Figure 7. Predictive distribution of eruptive volcanic basalts in the Spratly Islands and adjacent areas

\section{Discussions}

As above-mentioned, the results of this research completely based only on the determination of gravity and magnetic data. The main purpose of the research is to bring out predictions about the potential structures of eruptive volcanic basalts in the area. This is the foundation for the detail geological researches in the next stages. Through this research it can take out some of the following discussions:

The possible structures of the eruption volcanic basalt are predicted by a comparative analysis of the multidimensional relationship between the high frequency of gravity/magnetic fields and their 3D total gradient.
However, there are still some difficulties in determining the correctly spatial location of these structures. On the Spratly Islands and adjacent area, based on the different characteristic between eruptive volcanic basalt and sedimentary rocks near the surface, it can be said that the blocks which are higher density and magnetization than those surroundings could be identified as eruptive volcanic basalt.

The Gravity and Magnetic anomalies (at shallow layer) also change continuously in the whole Spratly Islands area (Figure 4a,b), here, the negative-positive anomalies are interleaved. The comparative analysis of the correlation between values of gravity and magnetic anomalies showing the clear differentiation in 
their magnitude. There are some areas which have positive correlation (positive values) are more clearly than the negative correlation (negative value), (Figure 5a,b). These characteristics bring out a picture on the distribution of volcanic basalt structures (at shallow layer) in the islands and coral reefs are affected by geological formations.

Figure 7 shows the distribution of some eruptive volcanic basalt in the deep water of the East Vietnam Sea, where the gravity and magnetic anomalies have the large change in a small range. Here, the local positive magnetic anomalies lay over the background negative values. The residual gravity anomalies are the separate closed positives that locate on the background negative values, too. The correlation values between gravity and magnetic anomalies have little changes at low amplitude, although some undersea mountains have a positive correlation related to their local igneous rocks. This implies the existence of the seafloor spreading and magmatic activities in the deep-water area of the East Vietnam Sea.

In additions, throughout the spatial analysis of the gravity, magnetic anomalies as well as their correlation with $3 \mathrm{D}$ total gradient, faults distribution, it can see that the distribution of the eruptive volcanic basalt could be also related to the deep faults. In figure 7, the distribution of eruptive volcanic rocks is controlled and affected by the deep crustal structure and faults. These rocks are mostly concentrated on the intersections of the faults (fault system in Figure 1) and transitional zone between crust's types (Figure 7). The distribution of these rocks is mostly along a northeast-southwest direction, which relates to the deep fault's direction in the area. It is can say that magmatic activity extended to the surroundings areas during and after spreading of the oceanic floor.

\section{Conclusions}

This research has applied an effective geo- physical methods in combination to determine predictively the distribution of the eruptive volcanic basalts: Methods of reduction to the magnetic equator in low-latitudes to bring out a better correlation between magnetic anomalies and their causing-sources; High-frequency filtering is to separate gravity and magnetic anomalies as well as information about the volcanic basalts in the upper part of the Earth's crust; 3D total gradient is to define the spatial locations of high density and magnetic bodies.

The method of multi-dimensional correlation analysis between the high-frequency gravity, magnetic anomalies with weighted total gradient 3D allows determining quite accurately the ranges as well as the spatial locations of the eruptive volcanic basalts in the Spratly Islands and adjacent areas.

The diversity of the formation and the complex physical properties of the eruptive volcanic basalt causing the determination of their characteristics more difficulties. In order to determine the distribution of the eruptive volcanic basalts more accurately and efficiently, it is necessary to apply the geophysical methods together with seismic, geochemistry and drilling data in combination.

The eruptive volcanic basalts concentrate mainly in the area of the continental slopes and around the islands of the Spratly Islands. In the Northern part, they appear not only incoherently on the oceanic crust of the East Vietnam Sea, but also concentrate as a large zone in the tail of the South-East oceanic crust. In the center area, they concentrate in the North and South part of the Spratly Islands. Additions, in the Western part, they appear along to Tuy Hoa shear zone, Tu Chinh, and Nam Con Son uplift. In the South of the study area, it is hard to find the volcanic basalt locations, except areas near BorneoPalawan subduction zone. Similarly, in the Eastern part, they almost do not appear on the Reed Bank block and continental shelf of Malaysia and Philippines. 
Tran Tuan Dung and Nguyen Quang Minh/Vietnam Journal of Earth Sciences 39 (2017)

\section{Acknowledgments}

The authors wish to thank the VAST's Project No.VAST06.06/16-17 for funding this research.

\section{References}

Baranov, V., 1957. A new method for interpretation of aeromagnetic maps: Pseudo-gravimetric anomalies: Geophysics, 22, 359-383.

Bhattacharyya, B. K., 1966. Continuous spectrum of the total magnetic field anomaly due to a rectangular prismatic body. Geophysics, 31, 197-212.

Bracewell, R., 1999. The Fourier transform and its applications (3nd edition): McGraw-Hill. 496 p.

Bui Cong Que, Tran Tuan Dung, 2008. Study of crustal structure and Geodynamics in the East Vietnam Sea and adjacent areas. Vietnam Journal of Earth Sciences, 30(4), 481-490.

Dang Van Bat, Do Dinh Tat, Mai Thanh Tan, 1994. Characteristics of lithology and fossils of the Oligocene eruption. Vietnam Journal of Earth Sciences, 16(2), 59- 66. Hanoi.

Flower M.F.J., Zhang M., Chen C-Y., Tu K., Xie G., 1992. Magmatism in the South China Basin, 2. Postspreading Quaternary basalts from Hainan Island, south China. Chem. Geol., 97, 65-87.

Ian N. MacLeod, Keith Jones, Ting Fan Dai, 1993. 3-D Analytic Signal in the Interpretation of Total Magnetic Field Data at Low Magnetic Latitudes. Exploration Geophysics, 24, 679-688.

Karoly I. K, 1990. Transfer properties of the reduction of magnetic anomalies to the pole and to the equator. Geophysics. 55(9), 1141-1147.

Le Huy Minh, Luu Viet Hung, Vo Thanh Son, 2003. Reduction to the pole at low latitude and interpretation of the magnetic anomaly map of Vietnam. Vietnam Journal of Earth Sciences, 24(2), 164-174.

Lee T-Y., Lo C-H., Chung S-L., Chen C-Y., Wang P-L., Lin W-P., Hoang N., Cung T.C., Nguyen T.Y., 1998. ${ }^{40} \mathrm{Ar} /{ }^{39} \mathrm{Ar}$ dating result of Neogene basalts in Vietnam and its tectonic implication. In: M.F.J. Flower et al (Eds.). Mantle Dynamics and Plate Interactions in East Asia. Geodynamics Ser., 27, 317330. Amer. Geol. Union.
Leu, L.-K., 1981. Use of reduction-to-equator process for magnetic data interpretation: Presented at the 51st Ann. Internat. Mtg., Sot. Exnl. Geonhv.: Geophysics, 47.

Li S-L., Meng X-H., Guo L-H., Yao C-L., Chen Z-X., Li H-Q., 2011. Gravity and magnetic anomalies field characteristics of the East Vietnam Sea and its application for interpretation of igneous rocks, Applied geophysics, 7(4), 295-305.

Li Y., D. W. Oldenburg, 2001. Stable reduction to the pole at the magnetic equator, Geophysics, 66, 571-578.

MacLeod, I.N., K. Jones and T.F. Dai, 1993. 3-D analytic signal in the interpretation of total magnetic field data at low magnetic latitudes. Exploration Geophysics, 24(4), 679-688.

McElhinny, M.W., 1973. Palaeomagnetism and Plate Tectonics, Cambridge, London, 356pp. Chapter 1 presents an introduction to the geomagnetic field.

Nabighian MN, 1984. Toward a three-dimensional automatic interpretation of potential field data via generalized Hilbert transforms: Fundamental relations. Geophysics, 49, 780-786.

Nguyen Hoang, Phan Trong Trinh, 2009. Characteristics of lithological and geochemical of Neogene - Quaternary volcanic rocks and mantle dynamics in the East Vietnam Sea and adjacent. Journal of Geology, 312.

Pham Tich Xuan, Nguyen Trong Yem, 1999. Volcanic activities in late Cenozoic in Vietnam. Vietnam Journal of Earth Sciences, 12(2), 128-135.

Phillips, J. D., 1997. Potential-Field Geophysical Software for the PC, version 2.2: USGS open-File Report, 97-725.

Roest, W.R., J. Verhoef and M. Pilkington, 1992. Magnetic interpretation using the 3-D analytic signal: Geophysics, 57(1), 116-125.

Sandwell, D. T., Garcia E., Soofi K., Wessel P., and Smith W. H. F, 2013. Towards $1 \mathrm{mGal}$ Global Marine Gravity from CryoSat-2, Envisat, and Jason-1, The Leading Edge, 32(8), 892-899. doi: 10.1190/tle32080892.1.

Spector A and Grant FS, 1970. Statistical models for interpreting Aeromagnetic data. Geophys, 35(2), 293-302. 


\section{Vietnam Journal of Earth Sciences, 39(1), 1-13}

Sudhir Jain, 1988. Total magnetic field reduction - The pole or equator? A model study, Canadian journal of exploration in geophysics, 24(2), 185-192.

Tran Tuan Dung, 2013. Characteristics of the structure tectonic in the deep water of the East Sea of Vietnam based on interpretation of gravity and magnetic anomaly data. The $35^{\text {th }}$ Conference of Vietnam Petroleum Institute, 55-66.
Tran Tuan Dung, Bui Cong Que, Nguyen Hong Phuong, 2013. The Cenozoic basement structure of the Spratly Islands and adjacent areas by modeling and interpreting gravity data. Russian Journal of Pacific Geology. ISSN 1819-7140, 4, 227-236.

http://geomag.org/models/emag2.html.

http://www.ngdc.noaa.gov/geomag-web/\#declination. 